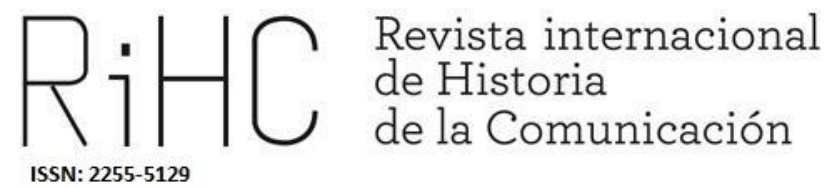

\title{
EL ORDEN OCCIDENTAL AL SERVICIO DE SU MAJESTAD: JAMES BOND Y LA CONSTRUCCIÓN DEL ENEMIGO
}

\section{Western Order at her Majesty Service: James Bond and the Building up of the Enemy}

DOI: http://dx.doi.org/10.12795/RiHC.2018.i11.10

Recibido: 01/10/2018

Aceptado: 23/11/2018

Publicado: $15 / 12 / 2018$

Coral Morera Hernández ORCID (iD http://orcid.org/0000-0002-5422-7943

Universidad de Valladolid cmorera@hmca.uva.es

Resumen: El presente trabajo analiza la caracterización de Spectra en la saga cinematográfica de James Bond desde el primer título hasta 1985. Para ello describimos las herramientas y recursos narrativos empleados con el objetivo de construir un enemigo a través de una fantasía. Las implicaciones políticas, históricas y culturales de una saga que se creó bajo el telón de fondo de la Guerra Fría, así como el respaldo de taquilla, favorecen su interés académico. El análisis revela la forma en que este género de acción presentó de forma velada al bloque soviético, sirviéndose de una narrativa truculenta y de cierta comicidad. 
Palabras clave: Cine, James Bond, Guerra Fría, comunismo, Spectra, soviético, espías, propaganda.

Abstract: The following study analyzes the characterization of Spectra in James Bond films from the first title until 1985. We describe the tools and narrative resources used on this subject to build up an enemy through a fantasy. The political, historical and cultural implications of a saga that was created under the backdrop of the Cold War, as well as its blockbuster, increases the academic interest. The analysis reveals how this action genre veiled the Soviet bloc by using a truculent narrative and a certain comedy. Keywords: Cinema, James Bond, Cold War, communism, Spectre, soviet, spies, propaganda.

\section{Introducción}

La saga cinematográfica de James Bond se creó bajo el telón de fondo de la Guerra Fría y tuvo hasta 1989 el enfrentamiento entre los bloques como núcleo argumental. El respaldo de taquilla de este género es innegable, lo que favorece que su estudio académico revista interés, sobre todo cuando ya han pasado casi dos décadas desde la caída del bloque soviético, y cuando se ha cumplido el centenario de la Revolución rusa.

La filmografía sobre la Guerra Fría tiene unas proporciones considerables en géneros de todo tipo, desde películas de terror, ciencia ficción, pasando por otras de suspense, comedias e incluso animación. No obstante, en la mayoría de los títulos la descripción del bloque soviético está realizada de forma explícita. En la saga británica no es así, más bien al contrario, es decir, se recurre a una fantasía para recrear una realidad, y más concretamente, una amenaza plausible: la del bloque soviético. Cuando Winston Churchill advirtió en 1946 de la peligrosidad que se cernía tras el Telón de Acero, no imaginó que décadas después se crearía en su país una serie de novelas que encontrarían adaptación en el cine con gran éxito, advirtiendo de la alarma soviética pero de forma enmascarada.

Resulta interesante analizar cómo llevaron eso a escena; como una especie de tebeo, con personajes caricaturizados, poco creíbles, inmersos en organizaciones mafiosas, que amenazaban con destruir el mundo. Todo ello sin desvincularse de los hechos que rodearon aquellos momentos y que mantuvieron a los dos bloques durante más de cuatro décadas al borde del abismo, a saber: la conquista del espacio, la carrera nuclear y la muerte de espías, entre otros.

Este trabajo se enmarca en el tipo de estudios caracterizados por contextualizar la cultura de masas dentro de debates sociopolíticos, y en dicho sentido se asemeja a análisis que han ofrecido perspectivas similares como el caso de Para leer al pato 
Donald (Dorfman y Mattelart, 2012). Llevamos a cabo un análisis de campo de la saga con el objetivo de determinar la forma de ocultar el comunismo a través de Spectra. Perseguimos describir cómo se sirvió el cine de una realidad, la Guerra Fría, para construir un enemigo, el bloque soviético. Proponemos para ello un análisis de las estructuras narrativas de este cine de entretenimiento durante un período determinado -desde 1962 hasta 1985- para conocer el alcance de la saga en la configuración del peligro "rojo".

James Bond ha sido, a través del cine, un protagonista importante en los sucesos acontecidos durante la Guerra Fría. Tal y como advierte Kinane: "un poderoso conducto discursivo a través del cual se puede canalizar una comprensión de las corrientes sociopolíticas de finales del siglo XX y contemporáneas" (2017). En sentido muy similar, Dodds confirma que "las películas de espías informan y refuerzan opiniones políticamente hegemónicas de la vida política global" (2005: 266). Exponemos los títulos analizados en la siguiente tabla:

$\begin{array}{lcc}\text { Título } & \text { Año } & \text { Director } \\ \text { Agente 007 contra el Dr. No } & 1962 & \text { Terence Young } \\ \text { Desde Rusia con amor } & 1963 & \text { Terence Young } \\ \text { Goldfinger } & 1964 & \text { Guy Hamilton } \\ \text { Thunderball } & 1965 & \text { Terence Young } \\ \text { Sólo se vive dos veces } & 1967 & \text { Lewis Gilbert } \\ \text { Al servicio secreto de su Majestad } & 1969 & \text { Peter R. Hunt } \\ \text { Diamantes para la eternidad } & 1971 & \text { Guy Hamilton } \\ \text { Vive y deja morir } & 1973 & \text { Guy Hamilton } \\ \text { El hombre de la pistola de oro } & 1974 & \text { Guy Hamilton } \\ \text { La espía que me amó } & 1977 & \text { Lewis Gilbert } \\ \text { Moonraker } & 1979 & \text { Lewis Gilbert } \\ \text { Sólo para sus ojos } & 1981 & \text { John Glen } \\ \text { Octopussy } & 1983 & \text { John Glen } \\ \text { Nunca digas nunca jamás } & 1983 & \text { Irvin Kershner } \\ \text { Panorama para matar } & 1985 & \text { John Glen }\end{array}$

\section{Marco teórico y estado de la cuestión}

El contexto de la Guerra Fría se desarrolló en torno a la amenaza nuclear, los avances en el espacio, la carrera militar y la "batalla" entre espías. En dicho entorno, con crisis controladas que no abrieron esa tercera guerra mundial que todos de un modo u otro auguraban de tanto en cuanto, el papel de la propaganda cobraba una importancia 
estelar. Y el cine, como ya ocurriera con la prensa y la radio, se erigía como el arma más poderosa.

Mucha de la cinematografía sobre la Guerra Fría realizada con anterioridad a la caída del muro de Berlín, se esmeró en trasladar a la población cómo era el bloque soviético y por qué había que temerlo. Un estudio concienzudo y de gran interés sobre las películas anticomunistas de los cincuenta pertenece a Pelaz López (2008) quien lista todos aquellos títulos que tomando como punto de partida Telón de acero, (William A. Wellman, 1948), ahondaban en el propósito de retratar a los comunistas: "no sólo como malvados sin escrúpulos, sino también víctimas de su sistema. El comunismo era en primer lugar un mal para los propios rusos", y añade sobre esta misma película: "contener a los soviéticos no era solo una necesidad geoestratégica, sino una cuestión de supervivencia de la propia democracia en el mundo" (2008: 131).

Otro análisis de gran empaque es el realizado por Martín Párraga (2010), esta vez sobre el cine de terror, que, aunque de forma velada, realizó una campaña anticomunista digna de interés. Quizá la película que se asemeje más a nuestro análisis sea La invasión de los ladrones de cuerpos, (Don Siegel, 1956), precisamente por la ausencia de narración explícita. A pesar de las lecturas antagónicas que se han vertido sobre el título, la película evidencia una crítica contra el comunismo, y en este sentido compartimos la propuesta del autor:

La lección que subyace tras la trama argumental se hace, por lo tanto, evidente: el enemigo puede no venir de la URSS sino de la casa vecina. Lo que es más, puede no ser un monstruo depravado que se alinea con el enemigo por maldad, sino una pobre víctima que ha sido poseída por las malvadas fuerzas del comunismo. Por otra parte, el desenlace de la película ofrece unas conclusiones aterradoras desde el punto de vista social: si se desencadena una invasión alienígena/comunista, el Estado pervivirá sin duda; aun a costa de aniquilar a los sujetos que se hayan visto infectados.

Otro estudio que aborda la temática Guerra Fría y cine es el llevado a cabo por Pelaz López, desde una cronología muy amplia y enmarcado en la ciencia ficción. Según el autor, "la ciencia ficción permitía canalizar el miedo latente en la sociedad americana ante una hipotética invasión soviética" (2013: 119).

Las exploraciones académicas sobre nuestro objeto de estudio no confirman que la saga cinematográfica Bond adopte de forma velada una crítica contra el comunismo. Es el caso de Pelaz López:

Aunque indudablemente la saga presenta una imagen poco amable de los soviéticos en general, lo cierto es que lo habitual en estas películas es que el enemigo de Bond sea algún tipo de organización criminal independientemente tipo Spectra. (...) En realidad lo más frecuente es que soviéticos y británicos se 
alíen para hacer frente a algún malvado enloquecido que intenta provocar un enfrentamiento entre las superpotencias, con el objetivo de que estas se eliminen entre sí (2016 : 51).

En el mismo sentido se ha postulado González Hevia, quien sostiene: "en su forma más genérica, el cine de la Guerra Fría da lugar a ciclos sobre agentes del tipo James Bond que dan por supuesta la maldad de los antagonistas sin caracterizaciones ideológicas ni referencias históricas precisas" (2013: 9) ${ }^{1}$. También habla de "genios malignos" Dodds (2005), sin atribuirles una ideología concreta.

Parece que en la serie creada por lan Fleming, que es la base sobre la que se inspira la saga cinematográfica, tampoco puede confirmarse este hecho a tenor del estudio realizado por Eco. El semiólogo italiano considera que no es algo evidente, y que si ocurre, es como parte de la exigencia narrativa:

Fleming no va nunca más allá del racismo ramplón del hombre común, lo que nos hace sospechar que nuestro autor no caracteriza a sus personajes de tal o cual manera como consecuencia de una decisión ideológica, sino por pura exigencia retórica. (...) Es singular que Fleming sea anticomunista con la misma tranquilidad que es antinazi y antialemán. No es que sea reaccionario en un caso y demócrata en otro. Simplemente es maniqueo por cuestiones de comodidad (1966: 91).

El presente trabajo precisamente profundiza en este aspecto y propone la siguiente hipótesis: en el cine de Bond hay una declaración ideológica concreta contra el Este a través de la caricatura de Spectra.

Hay bastantes trabajos académicos sobre James Bond, sin embargo, el estudio de la saga así como de los personajes de la misma se han convertido en variaciones de un mismo tema. Se han analizado los personajes femeninos en textos francamente repetitivos; también aspectos relacionados con la masculinidad, y en general, análisis centrados en los estudios culturales que no revelan elementos nuevos al debate mucho más allá de los que ya aportó el pionero trabajo de Eco sobre las novelas ${ }^{2}$.

\footnotetext{
${ }^{1}$ Hemos abordado un análisis comparativo entre los hechos históricos y algunos títulos de la saga localizando referencias históricas precisas en: Morera Hernández, 2018.

${ }^{2}$ Citamos aquí los estudios más representativos y originales: Acosta López, 2016; Chapman, 1999; Black, 2001; Bennet, 1983. Dodds (2005), por su parte, justifica el análisis del cine o de la cultura popular como una forma de acercarse y entender la política. Por último, una revisión exhaustiva de las publicaciones académicas sobre James Bond puede consultarse en: Kinane, 2017.
} 


\section{Metodología y objetivos}

Proponemos un "comentario textual fílmico" (Carmona, 2000: 45) centrado en el análisis de la estructura y el significado de la saga objeto de estudio. Coincidimos con Aumont en que "no existe un análisis universal para analizar films" (Aumont y Marie, 1990: 46) de ahí que planteemos un análisis en términos narrativos de naturaleza descriptiva, sin caer en lo que podría ser una mera divagación interpretativa. Abogamos por el análisis de contenido, "el más extendido de los enfoques fílmicos" (Ibidem: 130), y para ello nos ocupamos de la decodificación de los elementos narrativos desde un punto de vista icónico y discursivo, es decir, el contenido visual y textual. Seguimos una metodología que combina las propuestas de distintos autores ${ }^{3}$, ahondando en aquellos elementos que construyen Spectra, dado que en la presente saga la Guerra Fría se convierte en pretexto para poder abordar el peligro "rojo". Al no tratarse de películas de complejidad argumental o estructural, elegimos una vía de aproximación concreta que nos permita disociar distintos elementos y profundizar sobre ellos.

Nos ocupamos en primer lugar de la estructura narrativa de las películas que queda definida en el siguiente esquema:

1. Escena introductoria donde una organización criminal ha cometido alguna tropelía.

2. Títulos de crédito muy sofisticados sobre el tema musical principal.

3. Encargo de la operación del Servicio Secreto británico al agente Bond.

4. Primeras investigaciones de Bond.

5. Toma de contacto de Bond con Spectra.

6. Detención de Bond por parte de Spectra.

7. Duelo final Bond-Spectra.

8. Felicitación del Servicio Secreto británico a Bond por haber salvado al mundo.

9. Aventura amorosa de Bond con la protagonista femenina.

10. Títulos de crédito bajo el tema musical principal.

Observamos que la organización formal y la estructura de los títulos son simples y repetitivas en todos ellos, desde un formato que tiene una duración de dos horas y diez minutos aproximadamente. La banda sonora de la saga ha obtenido de ordinario una gran repercusión, sobre todo el tema central. Tal y como advierte Aumont "la función principal de la música en los típicos films comerciales es acentuar el efecto de unidad que también se intenta conseguir en el nivel de la narración y de la imagen" (Aumont y Marie, 1990: 209).

\footnotetext{
${ }^{3}$ Aumont, 1996; Caparrós Lera y Alegre, 1996; Pelaz López, 2006; Carmona, 2000.
} 
A continuación procedemos a incorporar dos categorías como parte del análisis. En una primera dividimos cada largometraje en unidades significativas; después descomponemos dichas unidades en componentes internos que faciliten la interpretación. Nuestro fin último es la localización de los elementos ideológicos. Atendemos a los núcleos argumentales, los tipos de personajes, la introducción del líder de Spectra y de sus esbirros, la indumentaria de éstos y la simbología utilizada.

\section{Spectra: una organización al servicio del Este}

El Dr. No, -el propio nombre ya lleva implícita la negación-, presenta en la película del mismo título y primera de la saga, a la organización Spectra: "Sociedad Permanente, Ejecutiva, contra el Espionaje, Terrorismo, Rebelión y Aniquilamiento". En este primer título ya encontramos una descripción muy explícita del modus operandi de dicha organización que da cuenta del nivel de terror y de los procedimientos que se emplean. Se trata de colaboradores que lo aguantan todo, tal y como señala Bond: "Uno toma cianuro, la otra se deja romper el brazo pero ninguno habla ¿Quién les mete tanto miedo?". Una sociedad despiadada: “¿Mataron a una inocente turista por retratar un paisaje?", -se pregunta Bond en Sólo se vive dos veces-; "ha sido liquidada como precaución rutinaria", responde Tanaka. La organización Spectra vuelve a ser definida en el título Nunca digas nunca jamás; en el resto de las películas de la muestra no se vuelven a especificar las siglas.

Si nos centramos en los núcleos argumentales de las películas analizadas, vamos a observar que se centran en provocar la destrucción de Occidente. Grosso modo, es una narración abiertamente maniquea de buenos y malos, siendo estos últimos quienes persiguen el dominio del mundo, y los primeros, el orden y la estabilidad. Sin embargo, analizando esta realidad simplista, encontramos rasgos que nos ayudan a identificar los elementos y recursos narrativos utilizados con el propósito de enmascarar al bloque soviético a través de Spectra.

En Goldfinger se persigue desestabilizar la economía mundial, es decir, el caos económico de Occidente a través de la "Operación Gran Slam" que además matará a sesenta mil personas. El "Proyecto NATO" en Thunderball, exige un rescate de doscientos ochenta millones de dólares bajo amenaza de destruir una ciudad de Estados Unidos o Inglaterra. En Al servicio secreto de su Majestad Blofeld advierte: "Las Naciones Unidas recibirán una felicitación de Navidad consistente en la información de los medios científicos que poseo para controlar o destruir la economía del mundo entero". En Diamantes para la eternidad se plantean destruir Washington. El siguiente 
diálogo que se da en La espía que me amó ahonda en el aspecto de la destrucción de Occidente: "¿Significa eso que los soviéticos pueden localizar nuestros submarinos nucleares y hundirlos?". "Yo diría que sí", contesta Bond. "O sea, que pueden inutilizar el sistema de defensa occidental". "Desgraciadamente si", asegura Bond. En otra escena de la misma película Carl Stromber sostiene: "la civilización tal y como la conocemos está corrompida y es decadente".

En Moonraker, Hugo Drax mantiene que "La conquista del espacio es el futuro; estamos hablando de hombres; estamos hablando de tecnología". "¿Qué se propone?", le pregunta Bond. "La muerte de la civilización", contesta Drax sobre la "Operación Arca de Noé". Uno de los esbirros de Kristatos que intenta matar a Bond en Sólo para sus ojos es un campeón de tiro con arco por Alemania Oriental, quien además advierte a su sobrina, patinadora profesional, que "nuestros planes han cambiado: vamos a irnos a vivir a Cuba unos meses". En Octopussy, un huevo Fabergé de la familia imperial rusa va a ser subastado. El propietario es un ruso con cuenta en Suiza. "Puede que lo vendan para obtener divisas para subvencionar operaciones secretas en el extranjero o pagar sobornos", le explica "M", -el jefe del Servicio de Inteligencia británico-, a Bond.

En Nunca digas nunca jamás se habla de la eliminación del "liberalismo radical" en clara alusión a Reagan y Thatcher. Una vez que Ernst Stavro Blofeld describe -como ya se hiciera en el primer título- qué es Spectra, aborda lo siguiente: "hemos hecho grandes inversiones en Oriente Medio y en América Central para fomentar las sublevaciones y la revolución". "Nuestros esfuerzos inversores se han visto compensados con las inversiones en venta de armamento y misiles", añade. Es difícil no ver la influencia de lo que estaba ocurriendo en aquellos años entre EE.UU. y la URSS, y por ende, en el mundo, y comprobar cómo los dos títulos de 1983 se hicieron eco del nivel de gravedad alcanzado aquel año ${ }^{4}$. A través de la "Operación lágrimas de Alá" se persigue cambiar las cabezas de torpedo de los misiles estadounidenses por cabezas nucleares. Quieren provocar "terror y extorsión". Si no pagan, harán explotar las cabezas nucleares provocando "una terrible pesadilla" y el quiebro económico mundial. La explosión de los pozos de petróleo pondrá en peligro la distribución del combustible desde Oriente Medio, es decir, la seguridad de Occidente.

En Panorama para matar se advierte de la peligrosidad de los soviéticos, de su supremacía y de la importancia de frenarlos. La vinculación entre Max Zorin, líder de Spectra, y el bloque soviético, queda probada de forma nítida en la siguiente escena: "Esta reunión no es aconsejable, general Gogol”, señala Zorin. "Es un riesgo calculado

\footnotetext{
${ }^{4}$ El 31 de agosto dos cazas soviéticos derribaron un avión comercial surcoreano causando la muerte doscientas sesenta y nueve personas. Un mes después se produjo una matanza de marines y paracaidistas franceses en Beirut. Dos días después, Ronald Reagan ordenó la operación "Urgent Fury" por la que se invadió la isla antillana de Granada para frenar los avances militares y maniobras soviéticas en Honduras, Nicaragua y otras partes de Centroamérica.
} 
pero necesario; descuida los procedimientos ya que usted no pidió aprobación antes de eliminar al agente 007", advierte Gogol. "Ya no me considero un agente de la KGB", señala Zorin. "Nosotros le entrenamos, le financiamos, iqué sería usted sin nosotros! ¿un experimento biológico? ¿un monstruo fisiológico?", grita un acompañante de Gogol. "Volverá con nosotros camarada, nadie abandona jamás la KGB", concluye Gogol. Aquí el objetivo es eliminar Silicon Valley y causar una gran destrucción en Occidente a través de la "Operación Proyecto Hallazgo Principal".

Estos "malvados enloquecidos" como los definía Pelaz López en párrafos anteriores, adoptan una actitud que bien puede identificarse con el bloque soviético, o si se prefiere, con la caricatura del mismo. Estamos ante una organización brutal, temeraria e imprevisible, capaz de utilizar los métodos más crueles, sobre todo contra sus propios miembros. El cine antisoviético ha presentado de ordinario a los comunistas como altamente desconfiados. Desde un ángulo estrictamente histórico, en la URSS, sobre todo durante determinadas épocas, las fronteras entre el bien y el mal podían variar en horas: "Un individuo podía ser un soviético como es debido hoy, y al día siguiente un enemigo del pueblo" (Zubock, 2008: 19). "Hice un curso en Siberia", dice Triple XXX; "Sí, tengo entendido que allí van muchos rusos", le contesta Bond en La espía que me amó. Además de las campañas de rusificación que incluían la deportación de habitantes de los países del Este: lituanos, estonios, letones y ucranianos, fueron muchos los prisioneros de guerra soviéticos trasladados desde los campos de concentración alemanes a Siberia (Ibídem: 23).

Un minuto y cincuenta y dos segundos es lo que tarda Spectra en matar a un falso Bond al inicio de Desde Rusia con amor. En la misma película, la narración describe la escena de unos peces siameses luchadores enfrentados: "unos seres fascinantes, valientes pero estúpidos", advierte № 1. Mientras dos de ellos luchan, "un tercero valiente espera a que el superviviente esté exhausto y entonces, al igual que Spectra, ataca". La criminalidad de Spectra queda hábilmente señalada en el encuentro entre Bond y Marc-Ange Draco, un mafioso bueno que estrecha lazos con el agente británico en Al servicio secreto de su Majestad. Bond advierte: "Jefe de la unión corsa, uno de los más importantes sindicatos del crimen de Europa". "El mayor", contesta Draco. "No del todo -argumenta Bond-. La organización Spectra opera en todo el mundo; sin embargo sus actividades legales tienen un ámbito más extenso (...)". Es una manera de advertir que Spectra, "el mal", comete crímenes pero está entre nosotros, convivimos con ellos, tienen actividades que les otorgan visos de legalidad.

En las películas están muy presentes los métodos empleados contra sus miembros, siempre en ese tono de caricatura que el presente trabajo persigue describir. "Si hace preguntas será fusilada y si se niega no saldrá con vida de la habitación", le plantea № 3, Rosa Klebb, -una exagente soviética que se ha pasado a Spectra- cuando está reclutando a Tania Romanova en Desde Rusia con amor. En esta 
película algunos miembros de Spectra llevan veneno en las puntas de las botas y calculan el tiempo que tarda en hacer efecto. "Aquí no se toleran los fracasos: conoce el castigo", señala № 1 a № 3. Crean intriga para finalmente terminar matando a № 5: “Doce segundos -dice № 1-. Algún día inventaremos un veneno más rápido". En la misma línea, Goldfinger gasea a todos sus aliados a quienes debía dinero en la película del mismo título. En Thunderball № 1 está haciendo un recuento de todo el dinero recaudado por los agentes de Spectra en actividades fraudulentas. Cuando pregunta a № 11, se deja un silencio breve para recrear el miedo del agente de Spectra cuyo reporte puede no resultar satisfactorio: "Distribución de narcóticos de China roja a EE.UU, -responde- dos millones trescientos mil dólares". "Esperábamos una ganancia mucho mayor", dice № 1. "¿Está bien seguro de que usted y № 9 han dado cuenta de todo lo percibido?" pregunta. Tras acusarles de desfalco añade: "Spectra es una organización cuya fuerza reside en la absoluta integridad de sus miembros; conozco al culpable y ya he dispuesto la acción oportuna" y electrocuta in situ a № 9. En Panorama para matar, durante la explicación de Zorin sobre la operación que se va a llevar a cabo contra Silicon Valley, uno de los asistentes se muestra disconforme. Es invitado a abandonar la reunión y le tiran directamente por una escotilla del avión.

Destacamos otro aspecto de relevancia hallado en Sólo se vive dos veces. El símbolo de OSATO, la "sucursal" de Spectra, la multinacional con la que Bond entra en contacto para sus actividades de espionaje, guarda una gran similitud con la hoz y el martillo. El detalle es muy significativo, y el número de escenas y secuencias en las que aparece también. El símbolo aparece la primera vez que Bond llega a la multinacional. Se puede ver varias veces, tanto en la habitación donde tiene lugar un enfrentamiento, como a la entrada y salida de Bond del edificio. El total de planos en los que se ve asciende a nueve. Pero vuelve a aparecer de forma insistente en otra escena de la película. De nuevo los planos recogen el símbolo en la puerta principal del edificio de la multinacional, en planos a la entrada y a la salida de Bond del mismo, así como en el helicóptero en el que llegan el presidente de OSATO y su secretaria. Sin embargo, la nota más llamativa es que aparece de forma recurrente, como ya ocurriera en la escena anterior, en un total de siete planos, y en uno de ellos dura 10 segundos $^{5}$. Como puede observarse, el símbolo resulta bastante disonante con el resto de elementos y guarda una más que llamativa semejanza con la hoz y el martillo. Juega con elementos plásticos muy básicos, círculos y líneas, que presentan connotaciones evidentes y apenas disfrazan sus referencias, aunque juegue con el equívoco de lenguas y culturas distantes.

\footnotetext{
${ }^{5}$ Minuto 37.
} 


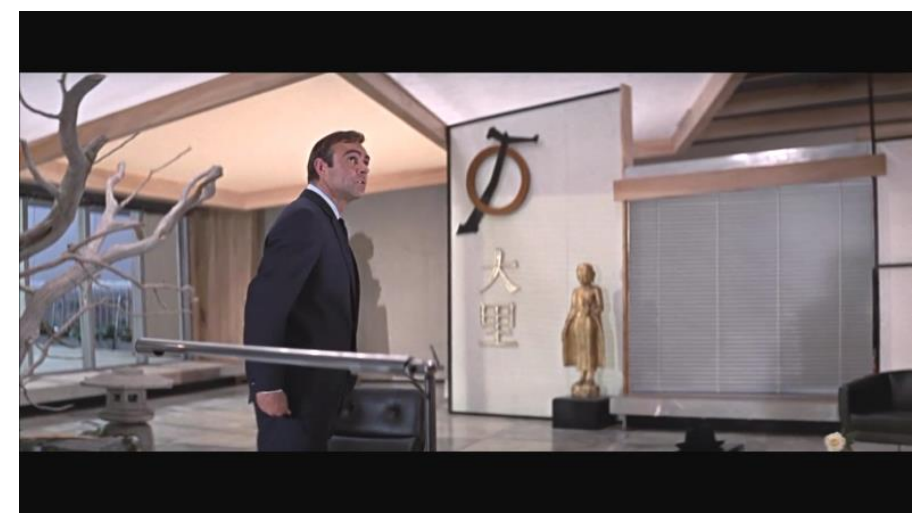

Figura n. 1 Fotograma Sólo se vive dos veces ${ }^{6}$

En la misma línea observamos un detalle curioso en El hombre de la pistola de oro. Scaramanga, líder de Spectra, aparece en el duelo final con Bond junto a un busto que aparece en dos planos de una misma escena y en uno sobre una diana, lo cual resulta bastante llamativo. El busto y Stalin parecen tener bastante similitud.

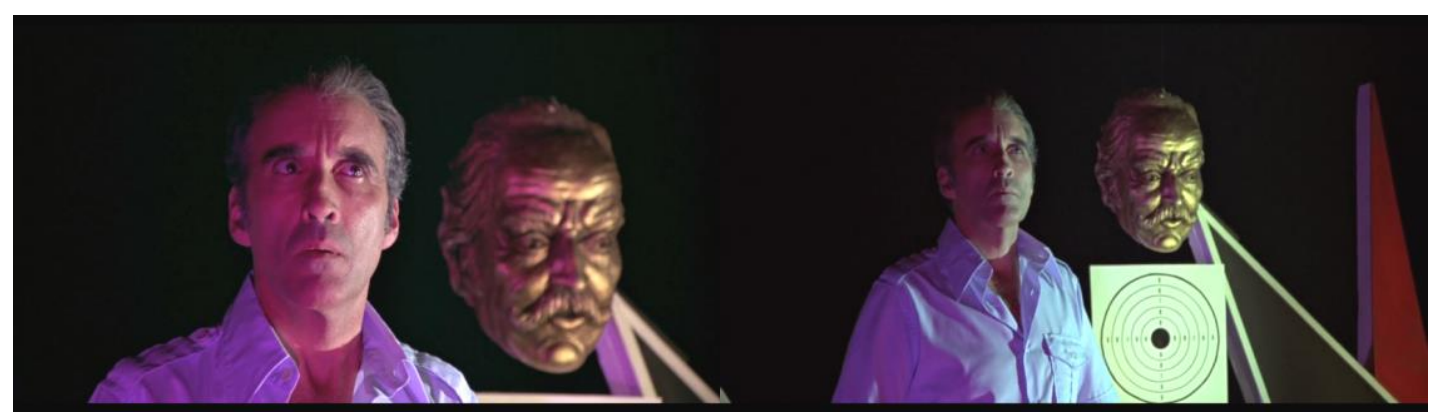

Figura n. 2 Fotogramas El hombre de la pistola de oro

\section{Características del antihéroe}

Comenzamos por adentrarnos en la descripción del líder protagonista de los títulos analizados, es decir, el personaje que actúa como máximo responsable de Spectra. Incluimos asimismo a sus "segundos" que actúan como los brazos ejecutores de la organización. En la presentación de los líderes de Spectra nos hallamos ante planos medios en su mayoría, que parecen enfatizar el perfil psicológico del personaje desde

\footnotetext{
${ }^{6}$ Los fotogramas incluidos en el presente artículo se publican al amparo del derecho de cita del artículo 32 de la Ley de Propiedad Intelectual, Real Decreto Legislativo 1/1996, 12 de abril:

1. Es lícita la inclusión en una obra propia de fragmentos de otras ajenas de naturaleza escrita, sonora o audiovisual, así como la de obras aisladas de carácter plástico o fotográfico figurativo, siempre que se trate de obras ya divulgadas y su inclusión se realice a título de cita o para su análisis, comentario o juicio crítico. Tal utilización sólo podrá realizarse con fines docentes o de investigación, en la medida justificada por el fin de esa incorporación e indicando la fuente y el nombre del autor de la obra utilizada.
} 
una perspectiva que permita lo dramático. Se trata de encuadres simbólicos, aquellos que se utilizan para dar profundidad psicológica según Caparrós (1996: 16). Siguiendo las directrices del mismo autor, se trata de un tipo de montaje "expresivo", dado que persigue una penetración subjetiva de la realidad; y dentro de dicho montaje es "rítmico", por cuanto se está alternando la velocidad de los planos para subrayar el impacto psicológico de la imagen (Ibidem: 18).

Estamos ante personajes oscuros, vengativos, siniestros, crueles y desconfiados. Advertimos que no tienen nacionalidad concreta, y sí una mezcla tanto de raza como de país, tal y como se desprende de las cintas en las que se hace mención expresa a su origen. Una de las herramientas más utilizadas para envilecer al enemigo desde hace siglos ha estado vinculada con la raza, o si se prefiere, con la inferioridad racial. En el presente estudio observamos que la narración al respecto persigue connotaciones negativas. Es el caso del Dr. No en la película del mismo título, "el hijo no deseado de un profesor alemán y una china", que se convirtió "en tesorero de la más poderosa sociedad secreta china" antes de emigrar a los EE.UU. Dirige Spectra como un campo de concentración. "Con su desprecio por la vida humana seguramente trabaja para el Este", señala Bond. Allí trabajan "los cerebros más grandes del mundo", advierte el Dr. No. "Dirá usted los más criminales", apostilla Bond. "El cerebro criminal que triunfa es siempre superior", contesta el Dr. No; a lo que Bond argumenta "¿Por qué tiene que ser criminal? Sin duda, el Oeste valoraría a un hombre de ciencia de su calibre". Queda denominada de forma expresa y contundente la criminalidad del Este en una escena que difícilmente pasa inadvertida.

Tampoco podemos hablar de una nacionalidad concreta en el líder de la siguiente película, № 1, en Desde Rusia con amor. De entrada advertimos que es un personaje invisible hasta el título de 1967, Sólo se vive dos veces, en el que le pondremos rostro. Los datos que obtenemos en pantalla son su voz y su mano acariciando a un gato Chinchilla. Los dictadores más crueles han mantenido de ordinario una excelente relación con sus mascotas. Mientras practicaban todo tipo de excesos, se recreaban en su faceta de amantes de los animales. Es decir, su desprecio por la vida humana y su amor por los animales estaban estrechamente relacionados. En todas las películas de la muestra se incluye esta relación enfermiza. Se nos presenta a una especie de psicópata, amante y protector de los animales, que puede aniquilar a miles de personas mientras idolatra a su mascota. "La muerte de Bond tiene que ser desagradable y humillante", dice № 1 mientras le da un pececito de la pecera a su gato que lo engulle rápidamente. Así las cosas, nuestros antihéroes tienen peceras gigantes con tiburones, pirañas, cocodrilos, serpientes, que son los encargados de eliminar a los enemigos de Spectra o a sus esbirros. Otro aspecto bastante cómico de la saga.

Goldfinger tampoco tiene nacionalidad, es "un tramposo, traficante de lingotes de oro; (...) gran atractivo para ingeniosos criminales"; quien advierte: "el hombre ha obrado 
prodigios en todos los campos del conocimiento humano excepto en el crimen". "La extorsión es mi negocio", dice № 1 en "Sólo se vive dos veces". En Diamantes para la eternidad, Ernst Stavro Blofeld, tiene dobles, algo que sintoniza muy bien con la imagen de los dictadores a quienes siempre se les ha atribuido -sin que haya datos fehacientes que lo corroboren- la utilización de dobles. "A las fuerzas nucleares como a todos los matones, sólo se les puede intimidar con la fuerza", señala Blofeld.

Scaramanga es también hijo de cubano y británica en El hombre de la pistola de oro. Reclutado por la KGB y convertido en asesino y pistolero durante quince años. "Descubrí que me gustaba matar", señala. Carl Stromber en La espía que me amó es presentado como "uno de los principales capitalistas y explotadores occidentales"; "la civilización tal y como la conocemos está corrompida y es decadente", explica Stromber. Hugo Drax, el protagonista de Moonraker, es un mafioso que vive en un palacio versallesco que guarda mucha similitud con el lujo y la ostentación de los zares rusos, y que se propone "la muerte de la civilización" 7 . Drax creará una nueva raza para una nueva dinastía donde habrá "ley y orden". Entona un discurso mesiánico donde anuncia que destruirá a cien millones de personas. Este tipo de disertación encaja muy bien con el bloque soviético y su identificación como nación mesiánica con un papel trascendental, que, además de justificar sus acciones, persigue homogeneizar el mundo. Se trata del ideal de civilización perfecta contra un Occidente defectuoso. El plano de la alocución es un contrapicado de Drax entonando su discurso desde una plataforma. Todos los que le están escuchando contemplan la escena cariacontecidos ${ }^{8}$.

El intento de destrucción de Occidente ya había quedado patente en Al servicio secreto de su Majestad. Blofeld, quien lleva a cabo experimentos que le permitan provocar una guerra bacteriológica, persigue "la total destrucción a través de un virus omega que provoca esterilidad". "(...) Si mis demandas no son aceptadas, procederé sistemáticamente a la extinción de todas las especies de cereales y ganados del mundo entero". "Incluyendo la raza humana", apostilla Bond pensativo. El complejo de superioridad ya había captado nuestra atención en la escena en la que Blofeld está poniéndose la chaqueta; una escena cargada de simbolismo, retomada en párrafos posteriores, en la que sostiene: "Los métodos de los grandes pioneros han desconcertado a menudo a los espíritus convencionales".

Kristatos en Sólo para sus ojos, es un griego anglófilo, "nos ayudó el año pasado en una operación de contrabando; (...) está metido en negocios navieros, seguros, explotaciones petrolíferas, sabe todo lo que pasa". Se dedica al contrabando de heroína "cuando no está demasiado ocupado trabajando para Rusia contra Grecia e Inglaterra". Se trata de un agente doble. Uno de sus brazos ejecutores es Lock, quien

\footnotetext{
7 El mismo tipo de residencia se observa en "La espía que me amó" y en la mansión del comienzo de Thunderball.

8 1:40'.
} 
lleva un gorro de estilo soviético durante la película, y está metido en "contrabando, trata de blancas, drogas, contrato de asesinatos".

Kamal Khan, una especie de príncipe afgano en el exilio, es el protagonista de Octopussy, y es "un estafador que vende mercancías de dudosa procedencia". Una de sus socias es Octopussy a quien Bond pregunta: “¿Cómo tiene tantas preciosidades?", refiriéndose a sus empleadas. "Les ofrezco una manera de ganarse la vida", contesta. “¿En la delincuencia?”, pregunta Bond. "En los negocios”, contesta Octopussy. El número de mujeres que de ordinario han formado parte del Ejército rojo no puede cuestionarse, de ahí podríamos concluir que su presencia en la saga adopte una posible doble interpretación: la incorporación de mujeres en el terreno bélico del bloque soviético, y la utilización de las féminas como objetos necesarios para la narración. Además del título mencionado, otras películas en las que aparecen mujeres como soldados de Spectra son Goldfinger y Moonraker.

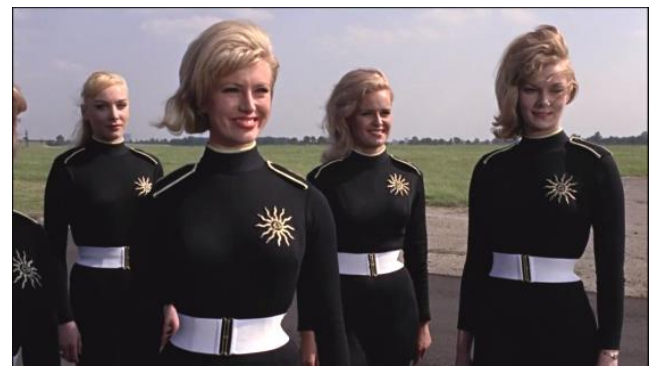

Figura n. 3 Fotograma Goldfinger

Maximilian Largo, el protagonista de Nunca digas nunca jamás ${ }^{9}$, posee el yate más caro de Bahamas, y un gusto por el lujo y los excesos. Con el dinero que sale de su casino, atiende obras de caridad para "niños huérfanos". Bond y él aparecerán en una escena jugando una partida del juego del mundo "cuyo único objetivo es el poder", dice Largo. "Lucharemos por conseguir el poder de las naciones; a medida que crecen los premios crece el castigo en la misma proporción: como en la vida real". "¿Cuál es su última empresa?" le pregunta Bond. "El petróleo", contesta.

Max Zorin es el protagonista de Panorama para matar. "Nació en Dresde, huyó a Alemania oriental durante los años sesenta, tiene pasaporte francés". "Era un agente de la KGB y se dedica a las especulaciones comerciales (...) Habla al menos cinco idiomas sin acento". La organización tiene a su cargo a un médico alemán que fabrica esteroides. Quien fuera un nazi durante la Segunda Guerra Mundial, experimentó con mujeres embarazadas en los campos de concentración para aumentar la inteligencia. Los efectos secundarios es que "nacieron niños más inteligentes pero también

\footnotetext{
9 La única cinta de la muestra que no fue producida por Eon Productions sino por una productora independiente. Es además un remake de Thunderball. Eon Productions fue fundada por Albert R. Broccoli y Harry Saltzman en 1961 con el objetivo de llevar al cine la adaptación de las novelas de Ian Fleming.
} 
psicópatas”. “¿Puede ser Zorin uno de esos niños?”, pregunta Bond, a lo que no obtiene respuesta. Zorin, además de a la investigación con esteroides se dedica al petróleo, con una planta que está destruyendo los cangrejos en la Bahía de San Francisco.

Los brazos ejecutores de Spectra están, si cabe, más caricaturizados que los líderes a quienes sirven. En Desde Rusia con amor, se trata de un rubio apolíneo soviético "convicto de asesinato, escapado de prisión y reclutado en Tánger". "Es de los mejores que hemos tenido, homicida paranoico, buena materia prima", señalan en Spectra. En este mismo título, № 3, la agente Rosa Klebb, engrosa también la lista de colaboradores de Spectra deformados por la saga. En igual sentido advertimos a Irma Bunt, responsable de la muerte de la única esposa de Bond, y quien señala en $A l$ servicio secreto de su Majestad: "es tan bonito matar a unos y a otros".

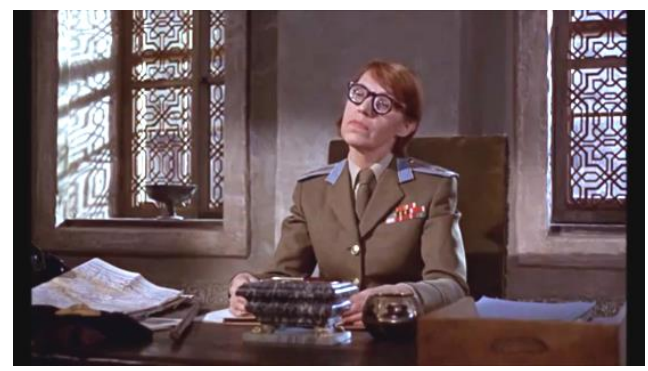

Figura n. 4 Fotograma № 3 en Desde Rusia con amor

Una vez advertidas esas mezclas de identidad donde no se puede establecer una nacionalidad concreta, vamos a enumerar los defectos físicos de los personajes. Es otro aspecto muy significativo en los villanos de las películas de la saga. El Dr. No carece de manos porque las ha perdido en un experimento radioactivo. Por su parte, el brazo ejecutor de Goldfinger es un coreano mudo. La primera vez que vemos a № 1 observamos que tiene un ojo desfigurado por una enorme cicatriz. Scaramanga, por su parte, tiene tres pezones. Su ayudante es un hombre con enanismo. Blofeld, en $A l$ servicio secreto de su Majestad, no tiene lóbulos. Igualmente notable es el físico del ejecutor "Tiburón", personaje que aparece en La espía que me amó y Moonraker, de una altura de dos metros y diecisiete centímetros, con los dientes de acero y sin diálogo en las películas. En pocas palabras, más parecido a un monstruo que a un humano.

Durante la Primera Guerra Mundial, los aliados, en defensa de la civilización y la democracia, utilizaron un ingente número de panfletos, películas y posters para estigmatizar a los alemanes hasta límites que desbordan lo meramente grotesco. En aras de despersonalizar a los germanos y presentarles como auténticos bárbaros, los autores que han analizado esta propaganda, Eberdhard (1988) y Darracott (1974), nos han descubierto a auténticos monstruos que bajo la consigna de "Detén al huno", presentaban las formas de violencia más espeluznante. Así se muestran a personajes 
con varias cabezas, garras en vez de manos, pisoteando niños, llevando a otros infantes ya muertos a cuestas y con más de dos piernas. En definitiva, a personajes no humanos. Dicha propaganda resultó bastante eficaz en la movilización de la opinión pública y de los propios soldados. Desgraciadamente, y tal y como advierte la profesora Ingrid Schulze, "Hitler encontró en la propaganda aliada de la Primera Guerra Mundial un ejemplo para desarrollar la suya en el III Reich"10.

La virilidad y la estética de James Bond contrasta con estos antihéroes: hombres que carecen de atractivo, poco agraciados, -efecto algo menos notable en el caso de Kamal Khan-, desagradables, y en muchos casos ciertamente asexuados. En algunos títulos incluso padecen sobrepeso. Frente al despliegue de conquistas y aventuras sexuales de Bond, los líderes de Spectra no aparecen en actos sexuales ni afectivos, y si lo hacen es maltratando y sometiendo a las mujeres; algo que también hace Bond, si bien, la narración lo ensalza y adorna de forma inicua.

Por último, nos ocupamos del atuendo de los líderes de la organización. Se trata de una chaqueta en forma y color muy similar a las que lucía Stalin, además de mantener cierto aire maoísta. En algún caso puede incluso retrotraernos a Fu-Manchú y la amenaza oriental. Este tipo de prenda es usada en los siguientes títulos: Agente 007 contra el Dr. No, Diamantes para la eternidad, Sólo se vive dos veces, Al servicio secreto de su Majestad y en Moonraker. En esta última, es, sin duda, donde el presente efecto cobra más fuerza. Hugo Drax luce este tipo de chaqueta, incluida una insignia dorada en la solapa. La escena en la que el líder de Spectra luce dicha prenda en Al servicio secreto de su Majestad esconde cierto misterio y es bastante simbólica. Blofeld aparece en pantalla con una bata de laboratorio que le es retirada por uno de sus ayudantes. En lugar de quedarse con la ropa que lleva debajo de la bata compuesta por camisa, chaleco rojo y corbata, se pone encima esta chaqueta de "comandante". La duración de la escena, y la parsimonia que emplea el líder de Spectra en terminar de abotonarse la chaqueta no deja indiferente ${ }^{11}$. Mientras esto ocurre, Bond escucha con cierto temor a Blofeld y sus planes. Los títulos analizados muestran a estos personajes vestidos para el combate, a través de un atuendo que no alberga espacio para adornos ni filigranas: está sometido a la función. Tal y como indicó Barthes, vestirse es un acto de significación (2003: 21).

\footnotetext{
${ }^{10}$ Schulze Schneider, I. Catedrática en Historia de la Comunicación Social, en discusión con la autora, 30 de noviembre, 2016.

${ }^{11}$ 1:01:11. La duración total de la escena asciende a 2 minutos y 10 segundos.
} 


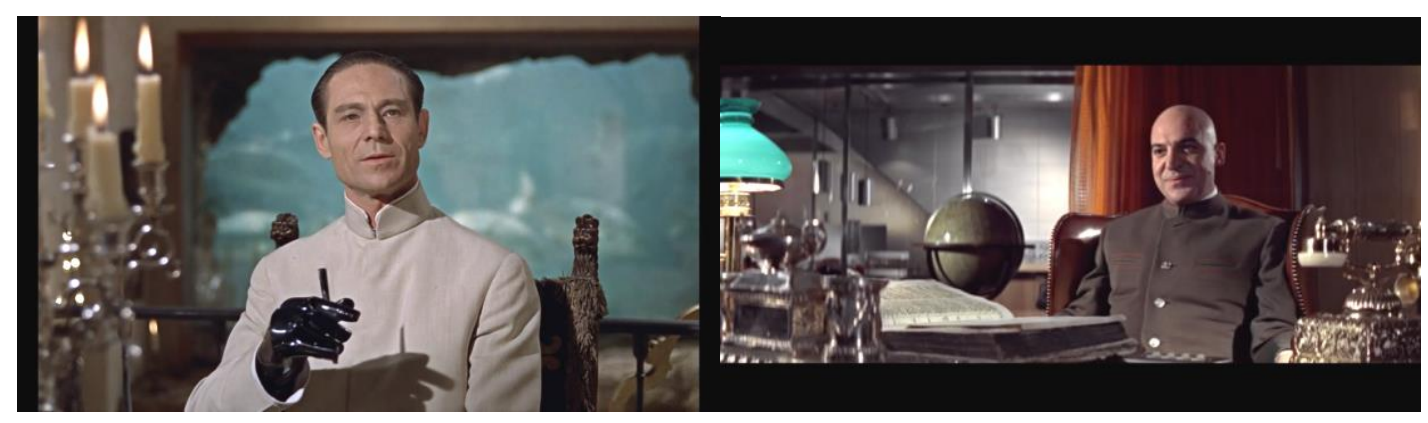

Figura n. 5 Fotograma Agente 007 contra el Dr. No. Figura n. 6 Fotograma Al servicio secreto de...

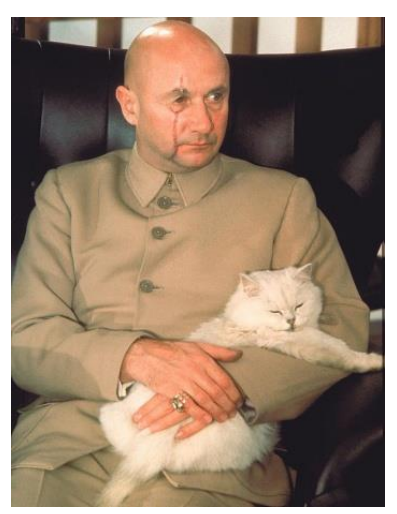

Figura n. 7 Fotograma Sólo se vive dos veces

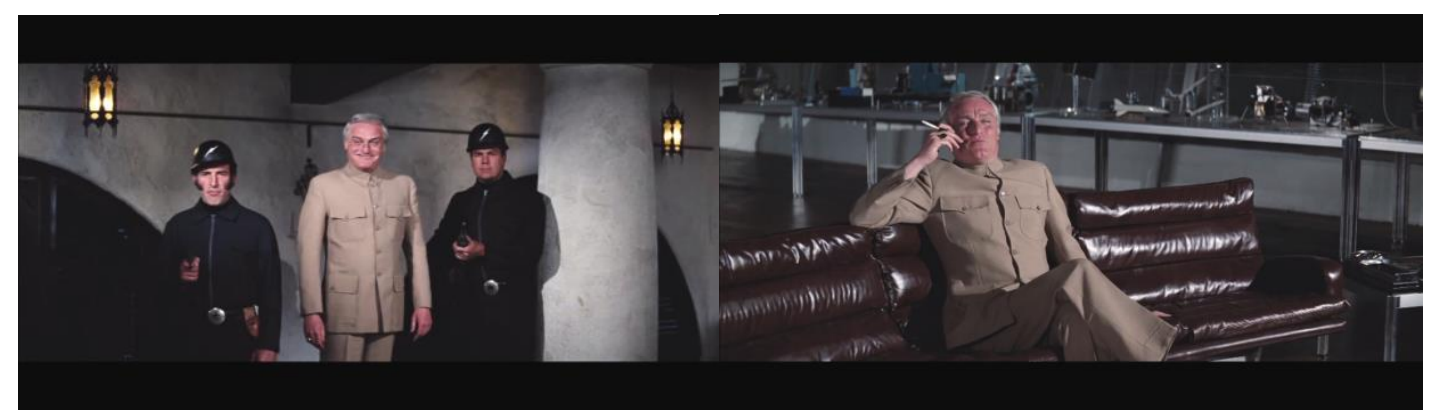

Figura n. 8 Fotogramas Diamantes para la eternidad

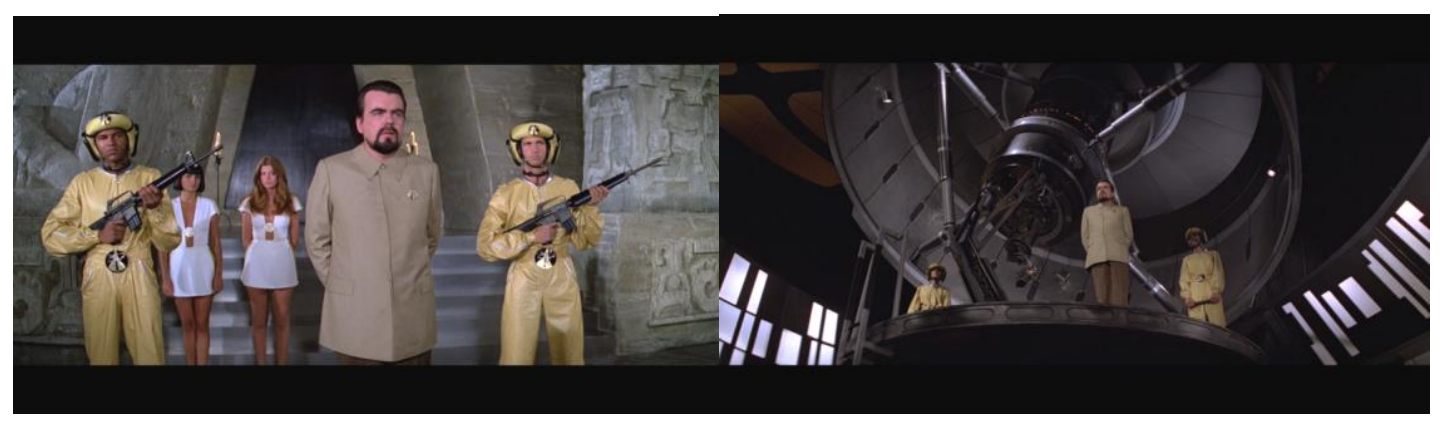

Figura n. 9 Fotogramas Moonraker

Enumeramos a continuación aquellos títulos en los que no se hace mención expresa a Spectra: Diamantes para la eternidad, Vive y deja morir y El hombre de la pistola de oro. Son tres películas consecutivas: 1971, 1973 y 1974. En los dos primeros títulos, de hecho, no está definida de forma nítida la pugna Este-Oeste. En otro sentido, la 
película que menos caricaturiza a Spectra es Thunderball. En este título, además, se invierte el atuendo en fondo y forma, siendo James Bond quien va de rojo en la mayor parte de la película.

Observamos asimismo que los obreros al servicio de Spectra son asiáticos en la mayoría de los títulos y van vestidos de rojo, en un atuendo muy similar al de los trabajadores chinos. Este extremo se comprueba en 007 contra el Dr. No, en Sólo se vive dos veces y en La espía que me amó.

\section{Octopussy y Nunca digas nunca jamás: dos narrativas explícitas}

En estas dos películas advertimos que es donde más expuesto está el bloque soviético. Ambas son del mismo año. Asimismo, en estos títulos la narración es más real y plausible. El año 1983 fue un año muy complicado y grave en las relaciones entre los bloques. En Octopussy las narraciones advierten de la superioridad soviética, de la división en el Este y de una posible catástrofe nuclear. En Nunca digas nunca jamás aparecen Centroamérica y Oriente Medio como partes de la trama y la consideramos la más explícita de la muestra.

Octopussy arranca con una escena en Cuba, después en Berlín Este y a continuación en Londres. Una vez descrita la operación en la que Bond debe participar, presenciamos una escena en el Kremlin, bajo el busto de Lenin. El general Gogol argumenta sobre las políticas de desarme desarrolladas por la NATO, cuando interviene el general Orlov: "es una política cobarde, anticuada y falsa". Queda patente la superioridad soviética a través de un mapa mundial que se tiñe de rojo. Mientras, van enumerando las fuerzas en Alemania Oriental con una "ventaja de diez a uno" sobre la NATO. Considera Orlov que si pusieran en marcha todas sus fuerzas obtendrían una victoria total en sólo cinco días. "Occidente está en decadencia", señala. "No veo necesario iniciar una guerra para satisfacer tu demencia personal y tu sed de conquista", advierte Gogol. "Por toda Europa hay cada día manifestaciones pidiendo el desarme nuclear unilateral lo que invalida la respuesta de la NATO", según Orlov. "Debemos reservar nuestras energías para hacer frente a nuestros problemas internos", dice Gogol. "El socialismo se implantará en todo el mundo de un modo pacífico camarada presidente", sentencia Orlov.

La tendencia a adoptar una actitud de ataque nuclear y no meramente defensivo queda patente en la trama. Colocan un misil de cien mil megatones en la base aérea de EE.UU. en Berlín oriental que harán explotar como si hubiera sido una bomba 
estadounidense que ha explotado accidentalmente. El vínculo entre Kamal Khan, líder de Spectra, y el bloque soviético liderado por Orlov es claro, de una forma tan nítida como veíamos en Sólo para sus ojos, la película de 1981, un año también complicado para las relaciones entre los bloques.

Con respecto a Nunca digas nunca jamás, queda definida la trama al comienzo de la película en un enfrentamiento entre guerrillas en Centroamérica, que son incorporadas para recrear un simulacro de entrenamiento que permita conocer las condiciones físicas de Bond. En esta película se advierte que el triunfo soviético sería lo más parecido a un apocalipsis. La operación aquí pasa por implantar un microchip en el ojo de un militar para que vea como el presidente de los EE.UU. y obtener información. Se advierte cómo Spectra manipula los misiles estadounidenses y éstos pasan por encima de las cabezas de los niños. La escena final de la película tiene un doble mensaje. Bond advierte que nunca más volverá a ejercer como agente secreto -de hecho fue la última película que protagonizó Sean Connery- y advierten: "si no vuelve Bond está en peligro el mundo civilizado".

\section{Resultados}

Nos encontramos ante una saga que no sólo participó de forma activa de las circunstancias históricas del momento sino que también supo construir con gran habilidad un enemigo desde una narración bastante bien ejecutada tanto estética como ideológicamente. Advierte Caparrós de la dificultad de distinguir en las películas de ficción entre "propaganda deliberada" y el denominado "testimonio inconsciente" (Caparrós Lera y Alegre, 1996: 7). No parece que sea el caso de los títulos que nos ocupan. Nos hallamos ante una saga producida para el entretenimiento en toda la extensión del término, por tanto, nuestro objeto de estudio es un producto de consumo altamente rentable desde el punto de vista económico e ideológico. Este entretenimiento es el que permite enmascarar, quizá, la semántica ideológica de la saga en el espacio textual, a través de claves paródicas en muchos aspectos, y afectivosexuales en otros.

Entendemos que los títulos analizados se encuadran en lo que Carmona clasifica como "films no narrativos de base retórica", cuya finalidad es "eminentemente persuasiva", y que persigue "la manipulación de los espectadores para inducirlos a asumir una convicción" (Carmona, 2000: 201). Este tipo de cintas apelan a un sistema de creencias y a las emociones; un sistema muy utilizado en cierta publicidad, tal y como sostiene el mismo autor. Aumont, por su parte, advierte que "una película de ficción se parece mucho a un ritual: debe conducir al espectador al desvelamiento de una verdad o de una solución" (Aumont, 1996: 125). 
En el cine de ficción hay, por tanto, unos esquemas fijos, una estructura básica. En el presente caso hay además un modelo común: un héroe que salva al mundo de los hostiles. Se trata de una narrativa muy convencional desde el punto de vista visual y discursivo, que sin embargo, y gracias al entretenimiento, oculta el objetivo ideológico, consiguiendo una representación de la realidad, una unanimidad, una verdad no discutible; en definitiva, una conformidad. Esta saga nació en plena Guerra Fría, y nuestro análisis confirma que responde a una postura ideológica, enmascarada, pero bien definida.

\section{Conclusiones}

En la mayoría de los títulos que tienen como contexto histórico y núcleo argumental a la Guerra Fría, exceptuando los títulos de terror o ciencia ficción, se desarrolla una descripción explícita y crítica, no precisamente favorable, sobre el bloque soviético. Lo que hasta ahora no se había sometido a revisión académica era el hecho de que una saga tan representativa y exitosa como la de James Bond, perteneciente al género de acción, llevara a cabo una caricatura del Este, hasta cierto punto, tan subliminal. Las altas dosis de entretenimiento, la utilización de personajes de gran atractivo, el liderazgo del propio James Bond, sobre todo en el caso de Sean Connery, los personajes femeninos, explotados física y psicológicamente hasta el extremo, y unos efectos especiales más que sobresalientes, han permitido quizá, que la caracterización ideológica pasara inadvertida.

En el cine de James Bond hasta 1989 la representación de la URSS como amenaza para la Guerra Fría es casi una obviedad. El hecho de que los conflictos se sostengan narrativamente a través de Spectra no descubre nada nuevo; lo que sí es relevante son los elementos hallados en los títulos de la muestra que confirman la naturaleza soviética de la organización criminal, es decir, una caracterización ideológica concreta. Un género de acción y de tanto respaldo permitió, no sólo presentar un espectáculo simplista entre el mundo libre y el totalitarismo, entre democracia y tiranía, sino que incluyó una sofisticada combinación de recursos en aras de llevar a cabo una ocultación del sistema soviético. El maniqueísmo de la trama, los gestos arrogantes del otrora imperio colonial, así como la caricatura de los nativos, especialmente en el Caribe y Asia, son otros de los resultados conclusivos.

Spectra es una comunidad siniestra y claustrofóbica que guarda gran similitud con los principios estalinistas: una organización superior al individuo, un servicio de espionaje implacable y extraordinario, y una represión brutal contra la disidencia. La construcción del enemigo, Spectra, es realizada de manera magistral desde distintos ángulos para enmascarar la amenaza comunista. En primer lugar, la representación de 
la psicología humana a través de personas que no son tal, más bien se trata de entes, números, robots perversos, seres pasivos, obedientes, sin identidad, con pensamientos lineales, a veces psicópatas, que reprimen sus sentimientos y cuyo único objetivo es el mal.

Por otra parte, los avances tecnológicos sorprenden a un Bond que adopta una actitud de miedo por el propio avance, y por estar en las peores manos: Spectra comete crímenes contra la humanidad. Por último, la ideología perversa, bien representada a través de muchos elementos y de las dosis adecuadas de conspiración y paranoia, algo, por otra parte, inherente a la Guerra Fría.

Parece acertado advertir que los elementos de esta fantasía sobre la malvada e irreal Spectra, y su identificación con el comunismo, están ahí. La saga cinematográfica de James Bond retrató la hipérbole del espía y estableció que el único que tenía licencia para matar era el agente británico. También reflejó el conflicto geopolítico e ideológico que se libró en la Guerra Fría. Más allá de los antagonismos y hostilidades entre el Este y el Oeste que tienen presencia y guardan similitud con el ciclo histórico, en el cine de James Bond, de una manera ciertamente truculenta, se construye un enemigo criminal, delincuente y execrable. El agente 007 jugó un papel crucial en la batalla de la imagen que se libró para hacer triunfar el modelo occidental sobre el soviético.

\section{Referencias bibliográficas}

ACOSTA LÓPEZ, A. (2016): "Desde Rusia con amor: El contexto geopolítico en los Balcanes de la Guerra Fría en James Bond" en Filmhistoria online, № 2, pp. 41-55.

AUMONT, J. et al. (1996): Estética del cine, Barcelona, Paidós.

AUMONT, J. y MICHEL, M. (1990): Análisis del film, Barcelona, Paidós.

BENNET, T. (1983): "The Bond Phenomenon: Theorising a Popular Hero" en Southern Review, no 16, pp. 195-225.

DEMM, E. (ed.) (1988): Der erste Weltkrieg in der internationalen Karikatur, Hannover, Fackelträger.

BARTHES, R. (2003): El sistema de la moda, Barcelona, Paidós.

BLACK, J. (2001): The Politics of James Bond, London, Bison Books.

CARMONA, R. (2000): Cómo se comenta un texto filmico, Madrid, Cátedra. 
CAPARRÓS LERA, J. M. y ALEGRE, S. (1996): “Análisis histórico de los films de ficción" en Cuadernos cinematográficos, no 10, pp. 7-26.

CHAPMAN, J. (1999): Licence to Thrill: A Cultural History of the James Bond Films, London, I. B. Tauris.

DARRACOTT, M. J. (1974): The First World War in Posters, Nueva York, Dover Publications Inc.

DODDS, Klaus, (2005): "Screening Geopolitics: James Bond and the Early Cold War films (1962-1967)" en Journal Geopolitics, № 10, pp. 266-289, http://dx.doi.org/10.1080/14650040590946584

DORFMAN, A. y MATTELART, A. (2012): Para leer al Pato Donald: comunicación de masas y colonialismo, Madrid: Biblioteca Nueva.

ECO, U. (1966): "James Bond: une combinatoire narrative" en Communications: Recherches sémiologiques l'analyse structurale du récit, no 8, pp. 77-93.

GONZÁLEZ HEVIA, L. (2013): "El cine sobre la "Guerra Fría" en el siglo XXI: una aproximación ontológica pluralista" en La balsa de piedra: revista de teoría y geoestrategia iberoamericana y mediterránea, no 5 (octubre-diciembre), pp. 1-13.

KINANE, I. (2017): "James Bond Studies: Evolutions of a Critical Field", en The International Journal of James Bond Studies, no 1, pp. 1-11, DOI: http://doi.org/10.24877/jbs.3

MARTÍN PÁRRAGA, J. (2010): “El cine de terror norteamericano de los 40 y 50 como instrumento de propaganda anti-comunista" en Espéculo: Revista de Estudios Literarios, no 46. Disponible en Internet (21-07-2018): https://webs.ucm.es/info/especulo/numero46/cineter.html

MORERA HERNÁNDEZ, C. (2018): “El cine que vivimos peligrosamente: James Bond y la Guerra Fría" en: MIGUEL BORRAS, M. (2018): ¿Qué es el cine? IX Congreso Internacional de Análisis Textual. Universidad de Valladolid, pp. 915-924.

PÉLAZ LÓPEZ, J. V. (2016): "La Guerra Fría: el cine y la batalla de los espías", en Velasco Molpeceres, A. M. y Reguero Sanz, I. (Coords.) La historia a través de los mass media: prensa, cine y moda (siglos XX y XXI), Madrid, Creaciones Vincent Gabrielle, pp. 47-57.

- (2013): "La gran invasión. El cine de ciencia ficción de la Guerra Fría al "choque de civilizaciones"'", en de las Heras Herrero, B. El siglo XXI visto desde el cine: la predicción de nuestro presente en la pantalla, Madrid, Ocho y medio. Libros de cine, pp. 115-138. 
- (2008): “Cae el telón. El cine norteamericano en los inicios de la Guerra Fría (1945-1954)" en Historia Actual Online, № 15, pp. 125-136.

- (2006): “El pasado como espectáculo. Reflexiones sobre la relación entre Historia y el cine” en Légete: Estudios de comunicación y sociedad, no 7, pp. 5-31. ZUBOCK, V. M. (2008): Un imperio fallido. La Unión Soviética durante la Guerra Fría, Barcelona, Crítica. 